\title{
Omega-3 fatty acid levels in red blood cell membranes and physical decline over 3 years: longitudinal data from the MAPT study
}

\author{
Bertrand Fougère • Sabine Goisser • Christelle Cantet • Gaëlle Soriano • \\ Sophie Guyonnet • Philipe De Souto Barreto • Matteo Cesari • Sandrine Andrieu • \\ Bruno Vellas • MAPT Study Group
}

Received: 20 June 2017 / Accepted: 10 August 2017 /Published online: 22 August 2017

(C) American Aging Association 2017

\begin{abstract}
Studies have shown that omega-3 polyunsaturated fatty acids (PUFAs) are associated with brain, cardiovascular, and immune function, as well as physical performance and bone health in older adults. So far, few studies have investigated the associations between PUFA status and performancebased tests of physical function. The objective of this study was to investigate the associations between omega-3 PUFA levels (eicosapentaenoic ar (EPA) docosahexaenoic acid (DHA)) in rer bloc cell (RBC) membranes and physical peformance, in a sample of community-dwelling old adults) This is a longitudinal observational study u data from the Multidomain Alzheimer's Lio Trial (MAPT), a randomized, placebo-c rollec trial. Four hundred participants from $\mathrm{M} / \mathrm{T}$, acebs group with available PUFA data were cluded. Omega-3 PUFA levels in RBC embrones were measured at
\end{abstract}

Members of th MAP I Study Group are listed at the end of the pap

B. Fou $\cdot$ e S S. Goisser · C. Cantet · G. Soriano •

S. Guyornet · P. De Souto Barreto · M. Cesari · B. Vellas Gérontopôle, Centre Hospitalier Universitaire de Toulouse, Toulouse, France

B. Fougère $\cdot$ C. Cantet $\cdot$ P. De Souto Barreto $\cdot$ M. Cesari $\cdot$ S. Andrieu • B. Vellas Inserm UMR1027, Université de Toulouse III Paul Sabatier, Toulouse, France baseline, and eir percentage of total RBC membrane $f$ acid , ontent was calculated. We dichotomized the sundardized omega-3 PUFA levels in RBC membranes as low (lowest quartile) vs. high ( $\mathrm{h}$. e upper quartiles). Gait speed (in $\mathrm{m} / \mathrm{s}$ ) and short hyy ical performance battery (SPPB) score (range 1 0 to 12 , higher is better) were used to assess physical performance at baseline and after 6, 12, 24, and 36 months. Participants were $75.2( \pm 4.3)$ years old and $68 \%$ were female. Bivariate analyses found that the characteristic of the participants in the lowest quartile of omega-3 PUFA levels (Q1) and those in the three upper quartiles (Q2-Q4) was not different at baseline; only those in Q1 were slightly older. In an unadjusted model, the difference in gait speed after 3 years of follow-up was significant $(-0.09 \pm 0.03 \mathrm{~m} / \mathrm{s} ; p=0.008)$ between participants in Q1 and those in Q2-Q4. In a model adjusted for age, gender, educational level, cognitive function, depressive status, body mass index, physical activity, grip strength, and their time interaction, this difference remained clinically relevant $(-0.07 \pm 0.04 \mathrm{~m} / \mathrm{s}$; $p=0.075)$. No difference between the two groups was found for the SPPB score development over 3 years. Older adults with subjective memory complaints and in the lower quartile of omega-3 have a faster decline on gait speed compared to people in the three upper quartiles. Other longitudinal studies are needed to explore this association and to examine mechanisms. 
Keywords Omega-3 polyunsaturated fatty acids · Gait speed $\cdot$ MAPT $\cdot$ Physical performance $\cdot$ SPPB

\section{Introduction}

As the elderly population has been expanding rapidly, the growing prevalence of age-related diseases and disability is a major public concern. Aging is associated with loss of physical function (Fried et al. 2004). With the aging of the general population and the considerable prevalence of older persons with physical decline, identifying modifiable factors that might delay or prevent loss of physical function is important to promote independence and quality of life for older persons.

Nutrient intake is a modifiable factor that may be important for maintaining the health of aging individuals. Over the past three decades, there has been substantial interest in the therapeutic potential of fish oils, rich in omega-3 polyunsaturated fatty acids (PUFAs), for various inflammatory conditions such as rheumatoid arthritis, inflammatory bowel diseases, and asthma in humans. Omega-3 PUFAs, especially eicosapentaenoic acid (EPA) and docosahexaenoic acid (DHA), have been associated with improved muscle composition or muscle stre igth (Reinders et al. 2015a; Rousseau et al. 2009; R-bin. et al. 2008). In addition, lower intakes of omeg, PUFAs, are cross-sectionally associated with worse physic. function (Robinson et al. 2008; Takayama t al. 2013). Data from the InCHIANTI study showed 1 t higher plasma omega-3 PUFA levels were associated w. wer risk of poor performance after 3 years or in et al. 2009). In AGES-Rer 'vik sudy, plasma omega-3 PUFAs, and in particul? $\mathrm{SH}_{\text {t }}$ were associated with lower risk of mobility dis?onity (inders et al. 2015a). Data on omega-3 PUFA $\mathrm{u}_{\mathrm{P}}$ ementar ed, suggest 2 henefit 1 1.2 g of EPA and DHA on gait speed am $\mathrm{g}$ ) rost-menopausal women (Hutchins-Wiese et al. 2013).

mea $n$ st preyous studies were limited to cross-sectional
mated Aega-3 PUFAs using questionnaires rather than
measurements of circulating PUFA, further studies are
needed. The aim of the present study is to determine the
associations between omega-3 PUFAs in red blood cell
(RBC) and physical performance over 3 years in a sample
of community-dwelling older adults with subjective mem-
ory complaints. We hypothesized that participants with higher omega-3 PUFAs in RBC would have lower risk of physical decline.

\section{Methods}

Participants

For this study, we used data from the M Altidomain Alzheimer's Disease Trial (MAPT), a ra miz d, placebo-controlled trial with four roups: or ga-3 PUFA supplementation, omega-3,PO sup lementation plus a multidomain intery ntion (ex cise advice, nutritional counseling, and ogniti $\mathrm{e}$ training), a multidomain intervention one, a placebo group (Vellas et al. 2014). To rule the effects of the interventions on physic $1 \mathrm{p}$ 'ormance, the present study was restricted to partipants I Igned to the placebo group with availab int rmation on baseline omega-3 PUFA levels (400 inc iduars).

The $\triangle P T$ pypulation included older adults aged 70 years ara y rer, living in the community, and at risk of cognitve decline. Inclusion criteria were either a Sp taneous memory complaint, a limitation in one inst amental activity of daily living (IADL) (Lawton a Brody 1969), or slow walking speed (i.e., lower or equal than $0.8 \mathrm{~m} / \mathrm{s})$. Exclusion criteria were a diagnosis of dementia (American Psychiatric Association 1994), a Mini Mental State Examination (MMSE) score lower than 24 out of 30 points (Folstein et al. 1975), dependency in at least one basic activity of daily living (ADL) (Katz et al. 1963), and the presence of any disease that could compromise the subject's participation in the multidomain intervention (e.g., Parkinson's disease). In addition, subjects who had taken omega-3 PUFA supplementation within the past 6 months were excluded (Andrieu et al. 2017).

The study protocol has been approved by the Ethical Committee in Toulouse (CPP SOOM II). Written informed consent was obtained from all participants. The protocol of the study is registered on a public-access clinical trial database (www.clinicaltrials.gov [NCT00672685]).

Measurements

RBC membrane PUFA analysis

At the baseline visit, participants underwent a blood drawing. RBCs were isolated from blood samples 
drawn into heparin-containing tubes. RBC membrane PUFA composition was analyzed by gas chromatography with flame ionization (Harris and Von Schacky 2004). Briefly, unwashed packed RBCs were directly methylated with boron trifluoride and hexane at $100{ }^{\circ} \mathrm{C}$ for $10 \mathrm{~min}$. The PUFA methyl esters thus generated were analyzed using a GC2010 gas chromatograph (Shimadzu Corporation) equipped with an SP2560 fused-silica capillary column (Supelco, Bellefonte, PA). PUFAs were identified by comparison with a standard mixture of fatty acids (FAs) characteristic of RBCs (GLC 727; NuCheck Prep).

The sum of the RBC membrane DHA plus EPA content was calculated and expressed as the percentage of total FAs in RBC membranes. We dichotomized the standardized omega-3 PUFA levels in low (lowest quartile, i.e., omega-3 index levels $\leq 4.89 \%$ ) vs. high (three upper quartiles) levels (Andrieu et al. 2017).

\section{Measures of physical performance}

\section{Gait speed assessment}

Gait speed was measured by timing participants while they walked $4 \mathrm{~m}$ along a corridor at their usual walkino pace (Gill 2010). The procedure was carried out ty ica and the best performance (the faster gait speed of two walking trials was used to calculate ga need in meters per second $(\mathrm{m} / \mathrm{s})$. These measures mere ve at baseline after $6,12,24$, and 36 month.

\section{Short physical performance battery}

The short physical perfo ance battery (SPPB) was used to assess physica' erf 'mance at baseline after 6 , 12, 24, and 36 monturs (o alnik et al. n.d.). It consists of three lower $x_{\mathrm{L}}$ nity pe, formance-based tests: gait speed, standi.g balan and ability to rise from a chair. Gait spee va measured as described above. For standing balance, artirpants were asked to stand in three pre res, vely 1 ,ore difficult positions for $10 \mathrm{~s}$ each: a posi n wur feet side by side, a semi tandem position, and $\mathrm{a} t \mathrm{~b}$-tandem position. Performance was also timed for the chair-stand test, which consisted of asking participants to stand up from and sit down in a chair five times in a row without using their hands. Each physical performance test result was then categorized into a fivelevel score, with 0 points representing inability to complete the test and 4 points representing the highest level of performance. A summary performance measure ranging from 0 (poorest) to 12 points (highest) was built by summing up the categorical scores of the individual performance tests.

\section{Confounders}

Sociodemographic information recorded at baseline included sex, age, and educational level. The ducational level of participants was defined in four clas $r-$ io diploma or primary school certificate, 2-sec dary education, 3-high school diploma 4- niver ity level. Body mass index (BMI) [comp ted as mo ared weight $(\mathrm{kg}) /$ height $^{2}(\mathrm{~m})$ ] was measu d to assess nutritional status. Depressive symp s assessed with the Geriatric Depression Scal GDS, max 15 points) (Clément et al. 1997), gnitive function with the Mini Mental State F-aminat /(MMSE, max 30 points) (Folstein et 1. 175), leisure-time physical activity (LTPA) was in ssured as metabolic equivalent taskminutes $r$ week(Plouvier et al. 2016), and hand grip strength in $\mathrm{K}_{\mathrm{y}}$ ograms was measured using a Collins dvnamom ter (Adult Size, $12.7 \times 5.7 \mathrm{~cm}$, Witte GMBH C. urgische Instrumente, Solingen, Germany) with nart cipants seated, their elbows by their side and flexed b. right angles, and a neutral wrist position (MassyWestropp et al. 2011). The participants were asked to perform the task twice with each hand. The average of the best results obtained for each side was used for the present analyses.

\section{Statistical analyses}

To describe the baseline characteristics according to the levels of omega-3, categorical variables are expressed in frequencies and percentages and continuous variables are reported as means and standard deviations (SD). To compare the baseline characteristics according to the levels of omega- 3 (or between the 2 groups), we used $t$ tests for parameters with Gaussian distribution (in some cases after transforming the variable of interest) or Wilcoxon rank-sum tests for quantitative variables and chi-square tests for qualitative variables.

To estimate (or to study) the change of physical performance (gait speed, SPPB total score) over the time according to the levels of omega-3, we used linear mixed models at three levels to take into account two types of correlation. We included a center specific random intercept to take into account the correlation center 
and a subject-specific random intercept and slopes to take into account the correlation intra-subject.

For each physical performance (gait speed, SPPB total score), we performed an unadjusted linear mixed model with the following fixed effects: omega-3 group, time, interaction between omega- 3 group, and time. We included time ${ }^{2}$ and time ${ }^{3}$ terms because the trajectory forms were not linear.

A second adjusted linear mixed model was performed in which we added potential confounders: age, gender, educational level, cognitive function [MMSE score], depressive symptoms [GDS score], BMI, leisure-time physical activity, hand grip strength, and their time interaction.

As there is no standard cutoff to define "low omega-3 level" and "high omega-3 level," we have done analyses by using the four omega-3 quartiles in our population. We have observed the same change from baseline in all three upper quartiles (results not shown). So, we dichotomized these standardized omega-3 PUFA levels in low (lowest quartile, i.e., omega-3 index levels $\leq 4.89 \%$ ) vs. high (three upper quartiles) levels (Andrieu et al. 2017).

Statistical significance was set at a $p$ value $<0.05$. All statistical analyses were performed using SAS software version 9.4 (SAS Institute Inc., Cary, NC).

\section{Results}

Cross-sectional analyses

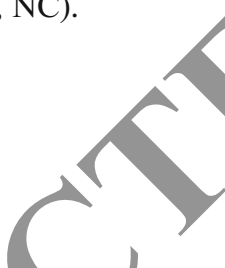

Baseline characteristics of the study sant are detailed in Table 1. More than half of the stu roup was female $(68 \%)$, with a mean age of out 7 years. The education level of participants wa th hioh (29\% with university level), as was the mean $\mathrm{M}_{4}$ 'SE score (28/30 points), and the mean GDS a t 3/15 points). Regarding physical functional $\mathfrak{n}$ forma mean gait speed was about $1.1 \mathrm{~m} / \mathrm{s}$ a m an SPPB score was 10.7/12 points.

At haseh thre was no significant difference betwr en $\mathrm{p}$ rticip, its in the lowest omega-3 quartile (Q1) and ise $\mathrm{m}$ the three upper quartiles (Q2-Q4) except for age alose in Q1 were older).

\section{Longitudinal analyses}

Linear mixed models were used to test the hypothesis that lower levels of omega-3 PUFAs would be associated with the risk of developing poorer lower extremity performance during 3 years of follow-up. In an unadjusted model, we found that participants in Q1 had lower physical performances than participants in Q2-Q4 quartiles regarding SPPB score and gait speed, but this difference was significant only for gait speed $(-0.09 \pm 0.03 \mathrm{~m} / \mathrm{s} ; p=0.008$; see Figs. 1 and 2). In the fully adjusted model regarding gait speed, this difference did not remain statistically significant ( $p=0.075)$. Regarding the results of both unadjusted and fully adjusted models for the SPPB score, pa icipants in Q1 had a lower score than participants in Q2- out t is difference was not statistically significa'tit (Table 2

\section{Discussion}

We found that older adults ith subjective memory complaints with $\mathrm{h}$ \% $\mathrm{h}$ vels of baseline RBC omega-3 PUFAs, compar- to thos 1 th low levels, had a slower decline on it seed over a 3-year follow-up; this difference was tt statistically significant after adjustment fo anfoun, ers.

One of tic easons for our negative findings regarding the SP PB was probably the good health status of the pa cipants, characterized by no functional impairment (exc usion criteria ADL score $<6$ points) and no cogni- e dysfunction (mean MMSE score 28 out of 30 points). The mean SPPB score at baseline was also particularly high (10.7 out of 12 points). Such a high mean SPPB score is also associated with a narrower range of distribution, which may generate a ceiling effect; thus, the predictive capacity for the outcome is lower.

In an unadjusted model, the difference in gait speed after 3 years of follow-up was significant and in an adjusted model, this difference did not reach statistical significance, but remained clinical relevant $(-0.07 \mathrm{~m} / \mathrm{s})$ according the smallest meaningful change estimate by Perera et al. ( $-0.05 \mathrm{~m} / \mathrm{s})$ (Perera et al. 2006).

The preventive role of omega-3 PUFA supplementation on several negative health outcomes, which is probably attributable to its positive effects on circulating lipids, blood pressure, and inflammation, have been confirmed in many clinical and epidemiological trials (Ascherio et al. 1995; Kromhout et al. 1985). By indicating that higher concentrations of omega-3 PUFAs may be protective against the deterioration of physical performance in older persons, our study expands the knowledge on the fundamental role of omega-3 PUFAs status. A potential mechanism for the observed associated between 
Table 1 Baseline characteristics of participants according to quartile (Q) of omega-3 PUFA levels in RBC membranes $(n=400)$

\begin{tabular}{|c|c|c|c|c|}
\hline & $\begin{array}{l}\text { All }(n=400) \\
\text { Mean } \pm \text { SD or } n(\%)\end{array}$ & $\begin{array}{l}\mathrm{DHA}+\mathrm{EPA} \mathrm{Q} 1(n=100) \\
\text { Mean } \pm \mathrm{SD} \text { or } n(\%)\end{array}$ & $\begin{array}{l}\mathrm{DHA}+\mathrm{EPA} \mathrm{Q} 2-\mathrm{Q} 4(n=300) \\
\mathrm{Mean} \pm \mathrm{SD} \text { or } n(\%)\end{array}$ & $p$ \\
\hline Gender (female) & $272(68.0 \%)$ & $61(61.0 \%)$ & $211(70.3 \%)$ & 0.08 \\
\hline Age (years old) & $75.2 \pm 4.3$ & $75.9 \pm 4.3$ & $74.9 \pm 4.3$ & 0.04 \\
\hline Education (university level) & $113(28.8 \%)$ & $27(27.8 \%)$ & $86(29.1 \%)$ & 0.12 \\
\hline BMI $\left(\mathrm{kg} / \mathrm{m}^{2}\right)$ & $26.0 \pm 3.94$ & $26.4 \pm 3.5$ & $25.8 \pm 4.0$ & 0.20 \\
\hline MMSE/30 & $28.1 \pm 1.5$ & $27.9 \pm 1.4$ & $28.2 \pm 1.6$ & 0.11 \\
\hline GDS/15 & $3.3 \pm 2.7$ & $3.2 \pm 2.7$ & $3.3 \pm 2.7$ & \\
\hline SPPB/12 & $10.7 \pm 1.5$ & $10.6 \pm 1.7$ & $10.7 \pm 1.5$ & 5 \\
\hline Gait speed (m/s) & $1.1 \pm 0.3$ & $1.1 \pm 0.3$ & $1.1 \pm 0.3$ & 0.59 \\
\hline Grip strength (kg) & $26.9 \pm 9.0$ & $27.0 \pm 8.9$ & $26.9 \pm 9.0$ & 0.93 \\
\hline LTPA, MET-min/week & $419.6 \pm 411.1$ & $460.8 \pm 454.5$ & $405.8 \pm 395$ & 0.79 \\
\hline
\end{tabular}

$B M I$ body mass index, DHA docosahexaenoic acid, EPA eicosapentaenoic acid, GDS Geriatric Deprec ion le, LIPA leisure-time physical activity, $M E T$ metabolic equivalent task, $M M S E$ Mini Mental State Examination, $P U F A$ polyun "urated fa. qcids, $Q$ quartile, $R B C$ red blood cells, $S D$ standard deviation, $S P P B$ short physical performance battery

omega-3 PUFAs in relation to physical performance is the RBC deformability. Indeed, RBC deformability decreases with exercise (van der Brug et al. 1995) and this is associated with increased aggregation and transit time through micropores (Yalcin et al. 2000), which may reduce the efficacy of oxygen delivery through the microcirculation. This increased deformability of RBCs was found to be a consequence of the incorporation of $\mathrm{mo}$. 3 PUFAs into RBC membrane phospholipids dersson et al. 2002). O. ga-5 PUFAs have also been shown to facilitat the trans ort of RBCs through the capillary bed (Brucknor fly. 1987), which could lead to enhanced oxygen delivery to skeletal muscle and a subsequent in. ovement in exercise performance. Other mechanism to c nsider is the omega-3 PUFAs' role in nervous sysa activity. They improve cognitive development and reference memory-related learning, increase neuroplasticity of nerve membranes, contribute to

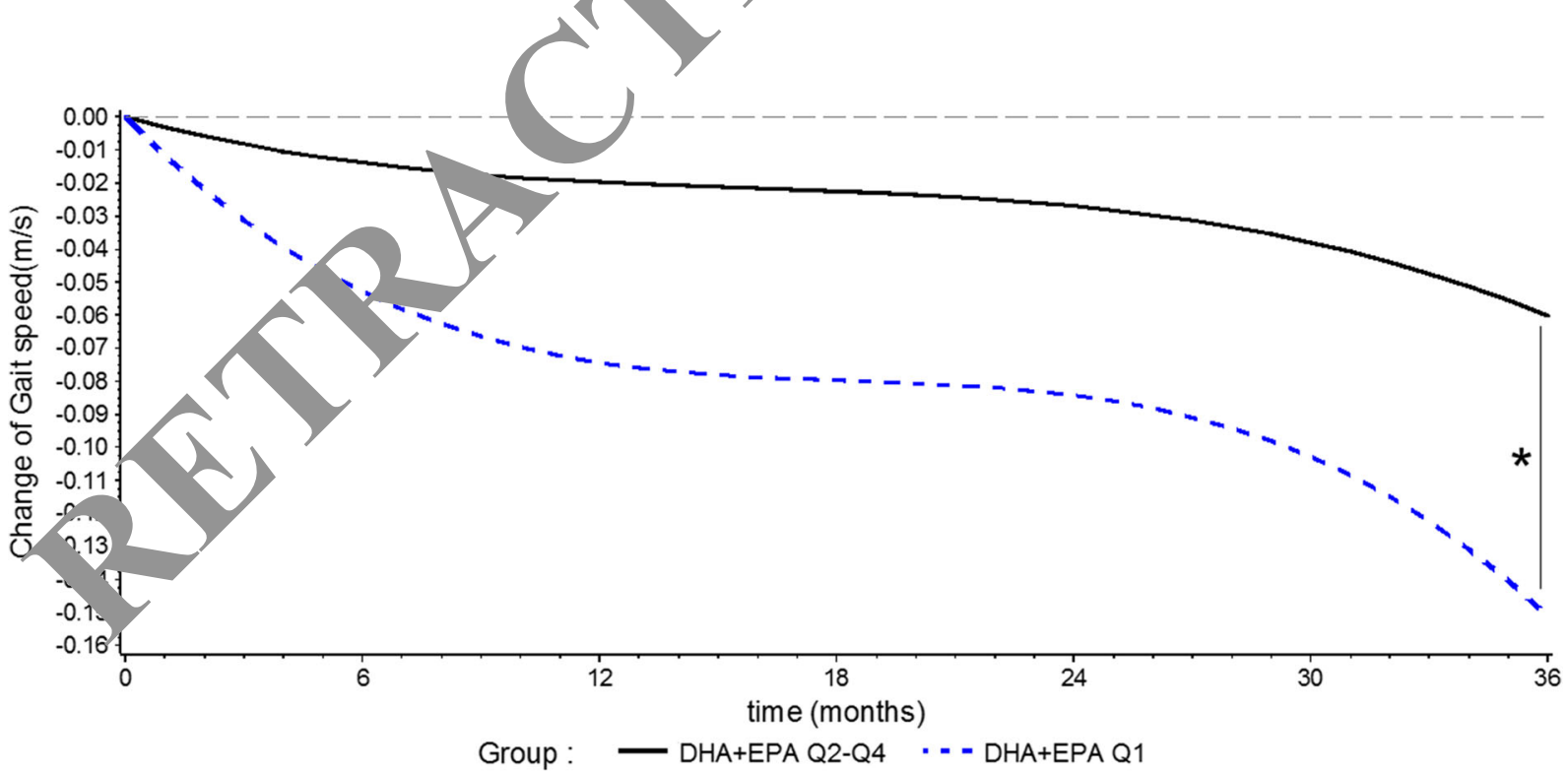

Fig. 1 Unadjusted model assessing the relationship between baseline omega-3 PUFA (DHA and EPA) levels and gait speed development $(n=400)$. DHA docosahexaenoic acid, EPA eicosapentaenoic acid, PUFA polyunsaturated fatty acid, Q Quartile. DHA + EPA high $=\mathrm{Q} 2-\mathrm{Q} 4 . \mathrm{DHA}+\mathrm{EPA}$ low $=\mathrm{Q} 1$. The asterisk indicates $p \leq 0.05$ 


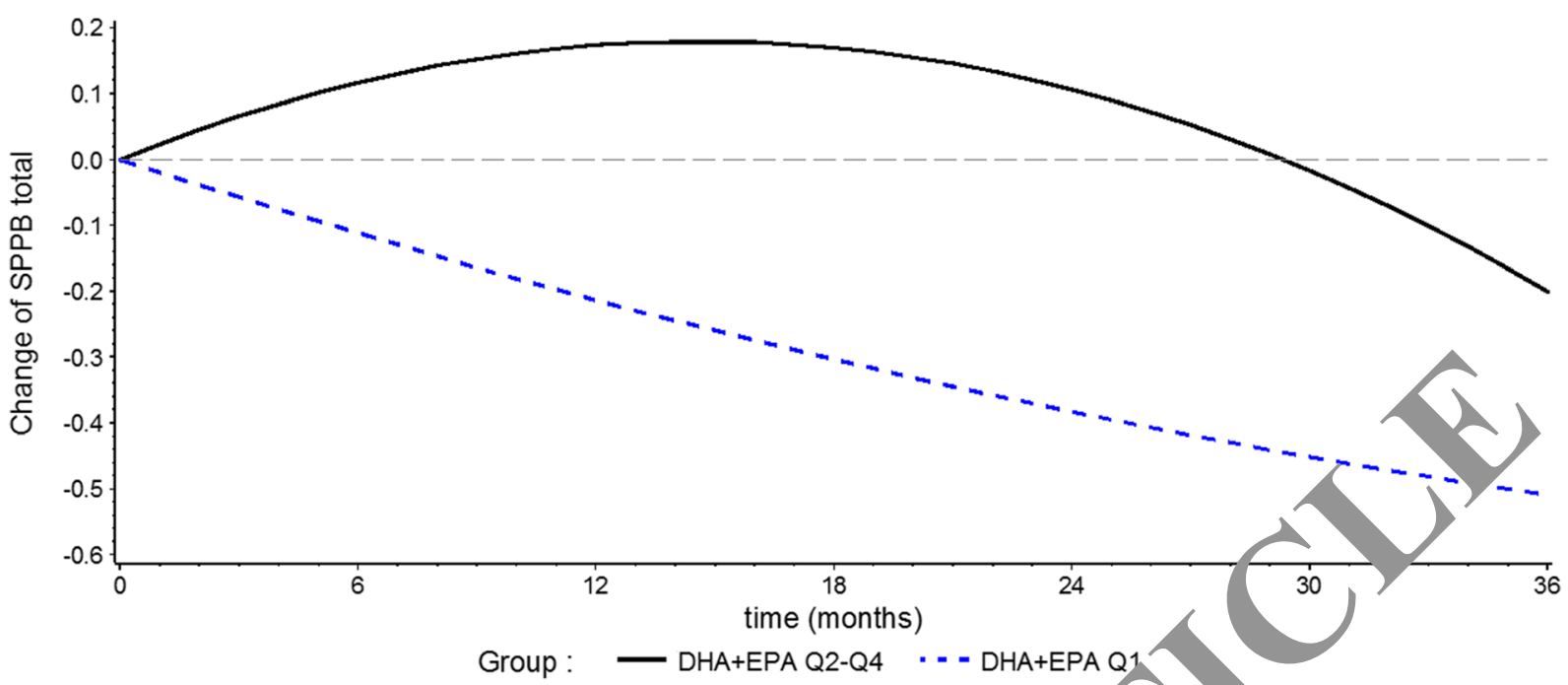

Fig. 2 Unadjusted model assessing the relationship between baseline omega-3 PUFA (DHA and EPA) levels and short physical performance battery score development $(n=400)$. DHA

synaptogenesis, and are involved in synaptic transmission (Fontani et al. 2005). Low plasma omega-3 PUFAs levels were associated with accelerated decline of peripheral nerve function with aging (Lauretani et al. 2007).

So far, only limited data exists on the effects of PUFAs on skeletal muscle composition and function. There i docosahexaenoic acid, ${ }_{2}$ eicosape aenoic acid, PUFA polyunsaturated fatty acid, Q quar SPPB short physical performance battery. DHA + F - 'igh $=$ Q. - Q4. DHA + EPA low $=$ Q1

evidence that a ficiency in dietary PUFAs impair skeletal musi nerforn ance in animals (Ruf et al. 2006; Ayre and Hulb ert 1,6 ), and some, but not all, existing studies found that a deficiency in both omega- 6 and omega-3 P. As was associated with reduced performance in skeletal muscle in rats (Ayre and Hulbert 1996). In a

Table 2 Adjusted and unadjusted model assessing the elationsı hotween baseline omega-3 PUFA (DHA and EPA) levels and gait speed and short physical performance battery score devel ph. $+(n=40,0)$

\begin{tabular}{|c|c|c|c|c|c|c|}
\hline \multirow[t]{2}{*}{ Time point } & \multirow{2}{*}{\multicolumn{2}{|c|}{$\begin{array}{l}\text { Change between baseline and fo low-up visit o, } \\
\text { within-group change from base }\end{array}$}} & \multicolumn{2}{|c|}{$\begin{array}{l}\text { Unadjusted difference of change } \\
\text { between baseline and follow-up visit }\end{array}$} & \multicolumn{2}{|c|}{$\begin{array}{l}\text { Adjusted difference of change } \\
\text { between baseline and follow-up } \\
\text { visit }\end{array}$} \\
\hline & & & $\begin{array}{l}\mathrm{DHA}+\mathrm{EPA} \text { Q1 } \\
\text { vs. Q2-Q4 }\end{array}$ & $p$ value & $\begin{array}{l}\mathrm{DHA}+\mathrm{EPA} \text { Q1 } \\
\text { vs. Q2-Q4 }\end{array}$ & $p$ value \\
\hline \multicolumn{7}{|c|}{ Gait speed (me } \\
\hline M6 & & $-0.01 \pm 0.01$ & $-0.04 \pm 0.02$ & 0.06 & $-0.04 \pm 0.02$ & 0.07 \\
\hline M12 & & $-0.02 \pm 0.01$ & $-0.05 \pm 0.03$ & 0.04 & $-0.06 \pm 0.03$ & 0.05 \\
\hline $\mathrm{M} 24$ & & $-0.03 \pm 0.01$ & $-0.06 \pm 0.03$ & 0.07 & $-0.06 \pm 0.03$ & 0.09 \\
\hline M36 & 03 & $-0.06 \pm 0.02$ & $-0.09 \pm 0.03$ & 0.01 & $-0.07 \pm 0.04$ & 0.07 \\
\hline \multicolumn{7}{|c|}{$\mathrm{SPP}^{\prime}\left(\mathrm{n}_{\mathrm{i}}\right.$ an $/ 12$, ints $\left.\pm \mathrm{SE}\right)$} \\
\hline & J. $11 \pm 0.08$ & $0.12 \pm 0.04$ & $-0.23 \pm 0.09$ & 0.01 & $-0.17 \pm 0.10$ & 0.08 \\
\hline M12 & $-0.21 \pm 0.13$ & $0.17 \pm 0.07$ & $-0.39 \pm 0.15$ & 0.01 & $-0.28 \pm 0.16$ & 0.08 \\
\hline M24 & $-0.38 \pm 0.17$ & $0.11 \pm 0.09$ & $-0.49 \pm 0.20$ & 0.01 & $-0.32 \pm 0.20$ & 0.11 \\
\hline M36 & $-0.51 \pm 0.18$ & $-0.20 \pm 0.10$ & $-0.31 \pm 0.20$ & 0.13 & $-0.13 \pm 0.20$ & 0.51 \\
\hline
\end{tabular}

Adjusted for age, gender, educational level, GDS score, BMI, MMSE score, grip strength, leisure-time physical activity, and their time interaction

$D H A$ docosahexaenoic acid, EPA eicosapentaenoic acid, $\mathrm{m} / \mathrm{s}$ meters per second, $Q$ quartile, $S E$ standard error, $S P P B$ short physical performance battery 
cross-sectional study among French community-dwelling older adults, a higher proportion of the omega-3 PUFAs EPA and DHA in plasma was associated with a higher gait speed (Frison et al. 2017). These associations were independent of many potential confounders (sex, age, educational level, energy and protein intakes, physical activity, and comorbidities). Another study reported similar crosssectional results (Abbatecola et al. 2009): among 1273 older adults involved in the InCHIANTI study, higher total PUFA and omega-3 PUFA plasma concentrations were significantly associated with the faster completion of a $7-\mathrm{m}$ walking test. In a Japanese study, higher intake of omega-3 PUFAs was associated with shorter timed up and go tests (Takayama et al. 2013). In contrast, another study showed no associations between self-reported omega-3 PUFAs and physical performance measures such as chair rise, grip strength, and gait speed, casting doubt over the role of omega-3 PUFAs in physical function (Rousseau et al. 2009). In AGES-Reykjavik study, a population-based study of risk factors for disease and disability in old age, higher concentrations of omega-3 PUFAs and, particularly, DHA may protect women from impaired mobility but does not appear to have such an effect in men (Reinders et al. 2015b).

Several limitations of this study need to be mentioned Most important, this is a secondary analysis using tata from a randomized controlled trial designed to rev cognitive decline. We tried to compensate fo ' is issuc by including only the placebo group into the at vses. Secondly, the study participants were recruited an.ong community-dwelling older persons ith a sjbjective memory complaint as main inclusion ch This may introduce a representativeness b au wry findings may therefore not be applicabl com nunity-dwelling older adults without any me ry amnlaint.

However, there als also veral strengths of this study. First, the sample s. is larg, second, we controlled the analysis for any po tial confounders. Finally, some difference het ween other studies and our study should be underlined. e fist and major difference is that while ma y st dies w, re cross-sectional, with the MAPT study, we re avie to perform a longitudinal study on the associa $a_{\text {, }}$ of omega-3 PUFA levels and gait speed decline, as gait speed measurements were repeated under a protocol at the 3-year follow-up. As a second difference, many studies used plasma omega-3 PUFA concentrations to estimate PUFA exposure, whereas we measured the omega-3 PUFA content in RBC membranes. Plasma PUFA concentrations are indicative of PUFA intake over a few days to weeks prior to sample collection only, and are more promptly affected by any PUFA intake within the $24 \mathrm{~h}$ prior to collection than the concentrations in RBC membranes (Hodson et al. 2009; Harris et al. 2013). This means that the plasma levels of PUFAs are more prone to reflect only the short-term fluctuations in the diet than the RBC membrane PUFA concentration (Harris et al. 2013). Information on RBC membrane PUFA levels can therefore be considered as more accurat because it reflects PUFA intake over a period of sever mont $s$, with less biological variability thar plasma JAs (Harris 2007; Harris and Thomas 2010

\section{Conclusion}

In this longitudin. St. $\mathrm{se}$, we found that participants with low ome PUFA evels in the red blood cell membranes. 4 y nerformance-based test scores of physical funct than people with higher omega-3 PUFA 1 Fo gait speed, the difference between the two roups remained clinical relevant over 3-year follow-up nnce confounders were controlled for. For the $\mathrm{Sh} 3$, this association did not reach statistical signifianc. Other longitudinal studies are needed to explore t,ese associations and to examine mechanisms.

Acknowledgments This study was supported by grants from the Gérontopôle of Toulouse, the French Ministry of Health (PHRC 2008), and the Pierre Fabre Research Institute (manufacturer of the omega-3 supplement). The promotion of this study was supported by the University Hospital Center of Toulouse.

Members of the MAPT Study Group Bruno Vellas, Sophie Guyonnet, Isabelle Carrié, Lauréane Brigitte, Catherine Faisant, Françoise Lala, Julien Delrieu, Hélène Villars, Emeline Combrouze, Carole Badufle, Audrey Zueras, Sandrine Andrieu, Christelle Cantet, Christophe Morin, Gabor Abellan Van Kan, Charlotte Dupuy, Yves Rolland, Céline Caillaud, Pierre-Jean Ousset, Bertrand Fougère, Sherry Willis, Sylvie Belleville, Brigitte Gilbert, Francine Fontaine, Jean-François Dartigues, Isabelle Marcet, Fleur Delva, Alexandra Foubert, Sandrine Cerda, Marie-Noëlle-Cuffi, Corinne Costes, Olivier Rouaud, Patrick Manckoundia, Valérie Quipourt, Sophie Marilier, Evelyne Franon, Lawrence Bories, Marie-Laure Pader, Marie-France Basset, Bruno Lapoujade, Valérie Faure, Michael Li Yung Tong, Christine Malick-Loiseau, Evelyne CazabanCampistron, Françoise Desclaux, Colette Blatge, Thierry Dantoine, Cécile Laubarie-Mouret, Isabelle Saulnier, Jean-Pierre Clément, Marie-Agnès Picat, Laurence Bernard-Bourzeix, Stéphanie Willebois, Iléana Désormais, Noëlle Cardinaud, Marc Bonnefoy, Pierre Livet, Pascale Rebaudet, Claire Gédéon, Catherine Burdet, Flavien Terracol, Alain Pesce, Stéphanie Roth, Sylvie Chaillou, Sandrine Louchart, Kristel Sudres, Nicolas Lebrun, Nadège BarroBelaygues, Jacques Touchon, Karim Bennys, Audrey Gabelle, Aurélia Romano, Lynda Touati, Cécilia Marelli, Cécile Pays, 
Philippe Robert, Franck Le Duff, Claire Gervais, Sébastien Gonfrier, Yannick Gasnier, Serge Bordes, Danièle Begorre, Christian Carpuat, Khaled Khales, Jean-François Lefebvre, Samira Misbah El Idrissi, Pierre Skolil, Jean-Pierre Salles, Carole Dufouil, Stéphane Lehéricy, Marie Chupin, Jean-François Mangin, Ali Bouhayia, Michèle Allard, Frédéric Ricolfi, Dominique Dubois, Marie Paule Bonceour Martel, François Cotton, Alain Bonafé, Stéphane Chanalet, Françoise Hugon, Fabrice Bonneville, Christophe Cognard, François Chollet, Pierre Payoux, Thierry Voisin, Sophie Peiffer, Anne Hitzel, Michèle Allard, Michel Zanca, Jacques Monteil, Jacques Darcourt, Laurent Molinier, Hélène Derumeaux, Nadège Costa, Christian Vincent, Bertrand Perret, Claire Vinel, Pascale Olivier-Abbal

Author contributions BF has made substantial contributions to conception and design of the manuscript and carried out the data collection. BF and $\mathrm{CC}$ performed the statistical analyses. BF wrote the manuscript. BF, SG, CC, GS, SG, PdB, MC, SA, and BV have made substantial contributions to the final manuscript. All authors have read and approved the final manuscript.

\section{Compliance with ethical standards}

\section{Clinical trial registry number and website}

The study protocol has been approved by the Ethical Committee in Toulouse (CPP SOOM II). Written informed consent was obtained from all participants. The protocol of the study is registered on a public-access clinical trial database (www clinicaltrials.gov [NCT00672685]).

Conflict of interest The authors declare that they ha no co. flict of interest.

\section{References}

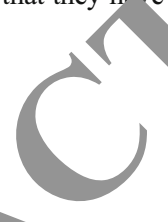

Abbatecola AM, Cherubi. Ruggiero C, Mag gio M (2009) Plasma polyunsaturated fatty acids an a re-relatec, $p$ hysical performance decline. Rejuvenation Res 1):25-32

American Psychratric Asse -ation (1994) Diagnostic and statistical na al f mental disorders: DSM-IV, 4th ed. American Psvchiat Assc ciation, Washington DC, p 866

And erssu A, Nà en C, Tengblad S, Vessby B (2002) Fatty acid

on of skeletal muscle reflects dietary fat composith in humans. Am J Clin Nutr 76(6):1222-1229

Andrieu s, Guyonnet S, Coley N, Cantet C, Bonnefoy M, Bordes $S$ et al (2017) Effect of long-term n-3 polyunsaturated fatty acid supplementation with or without multidomain intervention on cognitive function in elderly adults with memory complaints (MAPT): a randomised, placebo-controlled trial. Lancet Neurol 16:377-389

Ascherio A, Rimm EB, Stampfer MJ, Giovannucci EL, Willett WC (1995) Dietary intake of marine n-3 fatty acids, fish intake, and the risk of coronary disease among men. N Engl J Med 332(15):977-982

Ayre KJ, Hulbert AJ (1996) Effects of changes in dietary fatty acids on isolated skeletal muscle functions in rats. J Appl Physiol Bethesda Md 80(2):464-471

Bruckner G, Webb P, Greenwell L, Chow C, Richardson D (1987) Fish oil increases peripheral capillary blood cell velocity in humans. Atherosclerosis 66(3):237-245

van der Brug GE, Peters HP, Hardeman MR, Schep G, Mosterd WL (1995) Hemorheological response to prolonoed exercise - no effects of different kinds of feedings Int Sports Med 16(4):231-237

Clément JP, Nassif RF, Léger JM, Marchan F (1997) Do 'oprient and contribution to the validation of a ef French vesion of the Yesavage Geriatric Depression s 'e. L'I ncéphale. 23(2):91-99

Folstein MF, Folstein SE, McHu, PR (1975) "Mini-mental state". A practical method for ding the cognitive state of patients for the clinician. $D$ chlau Kes 12(3):189-198

Fontani G, Corradeschi F Felici A, fatti F, Migliorini S, Lodi L (2005) Cognitive an 'ysiolog cal effects of omega-3 polyunsaturated fatty acid vlementation in healthy subjects. Eur J Clin Mve g 35(11,.691-699

Fried LP, Ferr. L I Williamson JD, Anderson G (2004) Untangling concepts of disability, frailty, and comorbidity: nlication sor improved targeting and care. J Gerontol A Bipry ed Sci 59(3):255-263

Frison E, poirie Y, Peuchant E, Tabue-Teguo M, BarbergerGateau P, Féart C (2017) Plasma fatty acid biomarkers are ssociated with gait speed in community-dwelling older dults: the Three-City-Bordeaux study. Clin Nutr Edinb Scotl 36(2):416-422

Gill TM (2010) Assessment of function and disability in longitudinal studies. J Am Geriatr Soc 58(Suppl 2):S308-S312

Guralnik JM, Ferrucci L, Simonsick EM, Salive ME, Wallace RB (1995) Lower-extremity function in persons over the age of 70 years as a predictor of subsequent disability. N Engl J Med 332(9):556-561

Harris WS (2007) Omega-3 fatty acids and cardiovascular disease: a case for omega-3 index as a new risk factor. Pharmacol Res 55(3):217-223

Harris WS, Thomas RM (2010) Biological variability of blood omega-3 biomarkers. Clin Biochem 43(3):338-340

Harris WS, Von Schacky C (2004 Jul) The Omega-3 Index: a new risk factor for death from coronary heart disease? Prev Med 39(1):212-220

Harris WS, Varvel SA, Pottala JV, Warnick GR, McConnell JP (2013) Comparative effects of an acute dose of fish oil on omega-3 fatty acid levels in red blood cells versus plasma: implications for clinical utility. J Clin Lipidol 7(5):433-440

Hodson L, McQuaid SE, Karpe F, Frayn KN, Fielding BA (2009) Differences in partitioning of meal fatty acids into blood lipid fractions: a comparison of linoleate, oleate, and palmitate. Am J Physiol Endocrinol Metab 296(1):E64-E71

Hutchins-Wiese HL, Kleppinger A, Annis K, Liva E, LammiKeefe CJ, Durham HA et al (2013) The impact of supplemental n-3 long chain polyunsaturated fatty acids and dietary antioxidants on physical performance in postmenopausal women. J Nutr Health Aging 17(1):76-80

Katz S, Ford AB, Moskowitz RW, Jackson BA, Jaffe MW (1963) Studies of illness in the aged. The index of ADL: a 
standardized measure of biological and psychosocial function. JAMA J Am Med Assoc 185:914-919

Kromhout D, Bosschieter EB, de Lezenne Coulander C (1985) The inverse relation between fish consumption and 20-year mortality from coronary heart disease. N Engl J Med 312(19):1205-1209

Lauretani F, Bandinelli S, Benedetta B, Cherubini A, Iorio AD, Blè A et al (2007) Omega-6 and omega-3 fatty acids predict accelerated decline of peripheral nerve function in older persons. Eur J Neurol 14(7):801-808

Lawton MP, Brody EM (1969) Assessment of older people: selfmaintaining and instrumental activities of daily living. The Gerontologist 9(3):179-186

Massy-Westropp NM, Gill TK, Taylor AW, Bohannon RW, Hill CL (2011) Hand grip strength: age and gender stratified normative data in a population-based study. BMC Res Notes 4:127

Perera S, Mody SH, Woodman RC, Studenski SA (2006) Meaningful change and responsiveness in common physical performance measures in older adults. J Am Geriatr Soc 54(5):743-749

Plouvier S, Carton M, Cyr D, Sabia S, Leclerc A, Zins M et al (2016) Socioeconomic disparities in gait speed and associated characteristics in early old age. BMC Musculoskelet Disord 17:178

Reinders I, Song X, Visser M, Eiriksdottir G, Gudnason V, Sigurdsson S et al (2015a) Plasma phospholipid PUFAs are associated with greater muscle and knee extension strength but not with changes in muscle parameters in older adults. $\mathrm{J}$ Nutr 145(1):105-112
Reinders I, Murphy RA, Song X, Visser M, Cotch MF, Lang TF et al (2015b) Polyunsaturated fatty acids in relation to incident mobility disability and decline in gait speed; the Age, Gene/Environment Susceptibility-Reykjavik Study. Eur J Clin Nutr 69(4):489-493

Robinson SM, Jameson KA, Batelaan SF, Martin HJ, Syddall HE, Dennison EM et al (2008) Diet and its relationship with grip strength in community-dwelling older men and women: the Hertfordshire cohort study. J Am Geriatr Soc 56(1):84-90

Rousseau JH, Kleppinger A, Kenny AM (2009) Se $\mathrm{Se}^{1}$ reported dietary intake of omega-3 fatty acids and as ciation with bone and lower extremity function. J Am Geria $1781-1788$

Ruf T, Valencak T, Tataruch F, Arnold W (2) Running speed in mammals increases with muscle ${ }^{\prime} 6$ po nsat rated fatty acid content. PLoS One 1:e65

Takayama M, Arai Y, Sasaki S, Has noto M, Shimizu K, Abe Y et al (2013) Association o arin hir h-3 polyunsaturated fatty acids consump an functional mobility in the community-dwellir oldest olc Nutr Health Aging 17(1): $82-89$

Vellas B, Carrie illette-G. onnet S, Touchon J, Dantoine T, Dartigues F et 1 (2014) MAPT study: a multidomain approach for ${ }_{1}$ Crm.. Alzheimer's disease: design and baseline data. J Pr Mycheimers Dis 1(1):13-22

Yalcin O, Yuclikatay M, Senturk UK, Baskurt OK (2000) Effec s of s,vimming exercise on red blood cell rheology in trained and untrained rats. J Appl Physiol Bethesda Md 88(6):2074-2080 